\title{
Qualitative anti-tubercular activity of synthetic ethyl 7-acetyl- 2-substituted-3-(4-substituted benzoyl) indolizine-1-carboxylate analogues
}

\author{
Sandeep Chandrashekharappa ${ }^{1 *}$, Katharigatta N. Venugopala ${ }^{2,3}$, Rashmi Venugopala ${ }^{4}$, Basavaraj Padmashali ${ }^{1,5^{*}}$ \\ ${ }^{1}$ Department of Chemistry, Sahyadri Science College (Autonomous), Kuvempu University, Shimoga, India. \\ ${ }^{2}$ Department of Pharmaceutical Sciences, College of Clinical Pharmacy, King Faisal University, Al-Ahsa, Kingdom of Saudi Arabia. \\ ${ }^{3}$ Department of Biotechnology and Food Technology, Faculty of Applied Science, Durban University of Technology, Durban, South Africa. \\ ${ }^{4}$ Department of Public Health Medicine, University of KwaZulu-Natal, Howard College Campus, Durban, South Africa. \\ ${ }^{5}$ Department of Studies and Research in Chemistry, School of Basic Sciences, Rani Channamma University, Belagavi, India.
}

\begin{tabular}{l}
\hline ARTICLE INFO \\
\hline Received on: 07/11/2018 \\
Accepted on: 04/01/2019 \\
Available online: 28/02/2019 \\
\\
\hline Key words: \\
Indolizine analogs, qualitative \\
screening, agar dilution \\
method, whole cell anti- \\
tubercular screening, H37Rv \\
strain, Mycobacterium \\
tuberculosis.
\end{tabular}

\begin{abstract}
Both the emergence of multidrug-resistant and extensively drug-resistant tuberculosis (TB) are currently the major challenges in the treatment of TB. Only delamanid and bedaquiline have been recently approved as anti-TB drugs in the past 40 years. In an attempt to search for active anti-TB compounds against the sensitive strain of Mycobacterium tuberculosis, H37Rv - a series of synthetic ethyl 7-acetyl-2-substituted-3-(4-substituted benzoyl)indolizine-1carboxylates (2a-r) - have been screened for in vitro qualitative anti-TB activity using an agar dilution method. It was found that compounds $2 \mathbf{a}, 2 \mathbf{b}, 2 \mathbf{c}, 2 \mathbf{f}, 2 \mathrm{~g}, \mathbf{2} \mathbf{i}, \mathbf{2} \mathbf{j}, \mathbf{2}, \mathbf{2}, \mathbf{2}, \mathbf{2} \mathbf{p}$, and $\mathbf{2 r}$, which have various functional groups on the indolizine nucleus, were active against the H37Rv strain.
\end{abstract}

\section{INTRODUCTION}

Tuberculosis (TB) is a chronic, infectious disease caused by Mycobacterium tuberculosis that has been present for a long time. This disease remains the most large-scale medical and social problem. Approximately 3-4 million people around the world die each year from TB, and every year, approximately 8 million first-ever events of TB are registered. This burden is due to the high susceptibility of human immunodeficiency virus-infected

"Corresponding Authors

Sandeep Chandrashekharappa, Department of Chemistry, Sahyadri Science College (Autonomous) Kuvempu University, Shimoga, India.

E-mail: sandeep_m7@ rediffmail.com

Basavaraj Padmashali, Department of Studies and Research in Chemistry, School of Basic Sciences, Rani Channamma University, Belagavi, India.

E-mail: basavarajpadmashali@yahoo.com patients (Nunn et al., 2005). The emergence of multidrug-resistant and extensively drug-resistant TB has directed attention to, and scientific interest in, this infectious disease (Bloch et al., 1994; Kochi et al., 1993; Rastogi et al., 1992). For this reason, there is a need to discover new classes of chemical agents that features the diverse mechanisms of action to treat this disease.

Nitrogen-containing heterocyclic compounds have drawn the attention of medicinal chemists due to their various therapeutic properties (Nagesh et al., 2014; Siddesh et al., 2014; Thriveni et al., 2014). Indolizines are bicyclic heteroaromatic compounds containing six- and five-membered condensed rings with bridging nitrogen (Sandeep et al., 2013). Indolizine pharmacophore, with different degrees of substitution and unsaturation, is present in a wide variety of natural alkaloids (Michael, 2001; 2002) and unnatural azacyclic compounds (Halab et al., 2002; Pearson and Hembre, 1996). Synthetic indolizine analogs have been reported for their numerous pharmacological 


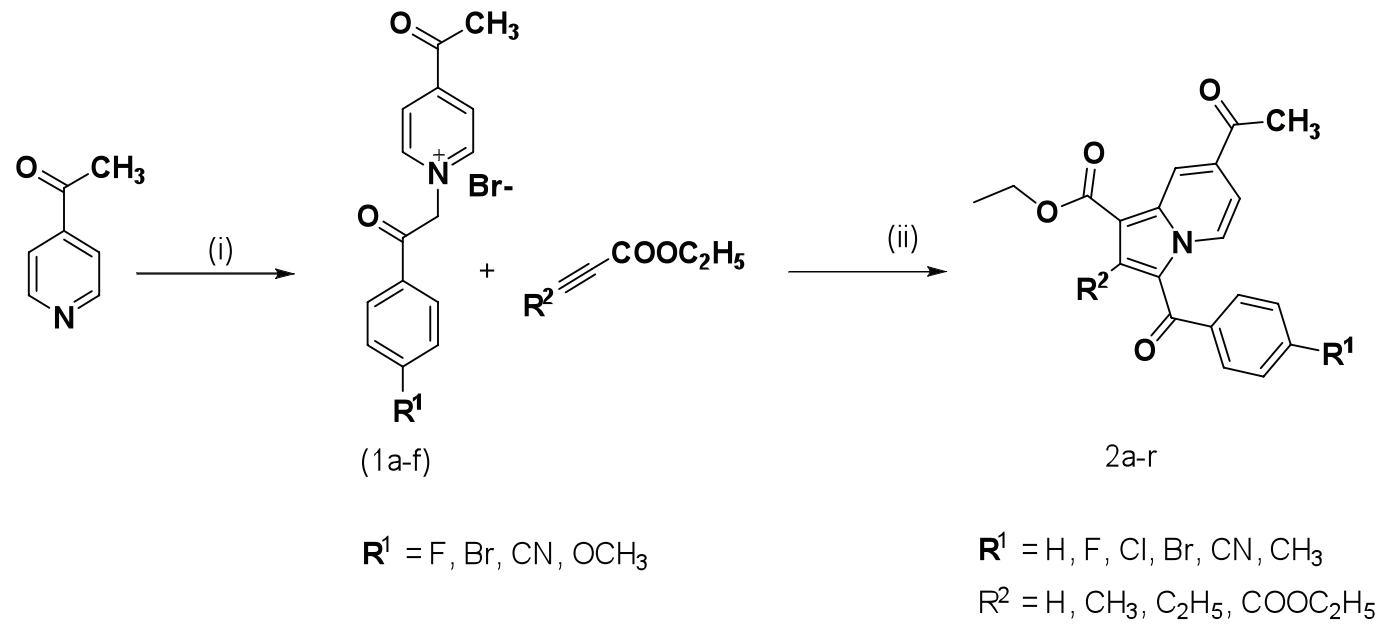

Scheme 1. Reagents and conditions: (i) 4-substituted phenacyl bromide, acetone, 5 hours stir; (ii) $\mathrm{K}_{2} \mathrm{CO}_{3}$, dimethylformamide (DMF), 30 minutes stir at room temperature.

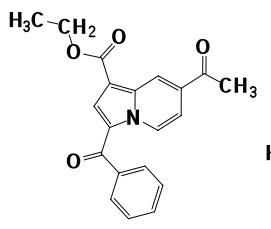

2a

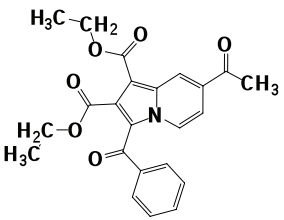

$2 \mathbf{b}$

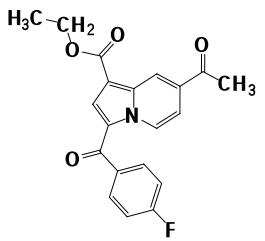

2c

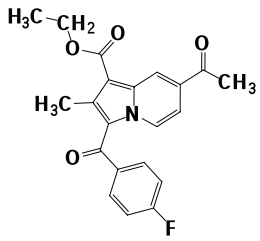

2d

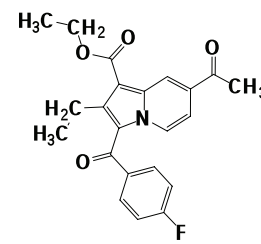

2 e

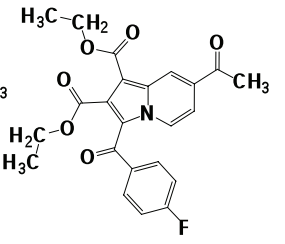

$2 f$

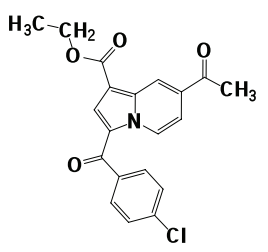

$2 g$

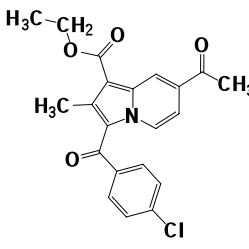

$2 h$

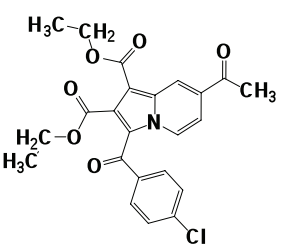

$2 i$

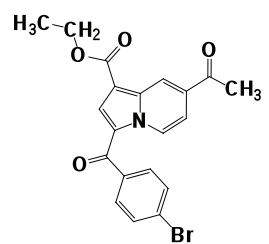

2j

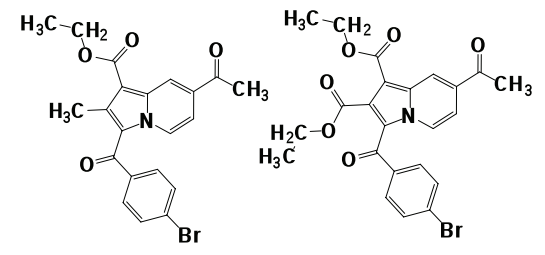

2k

21
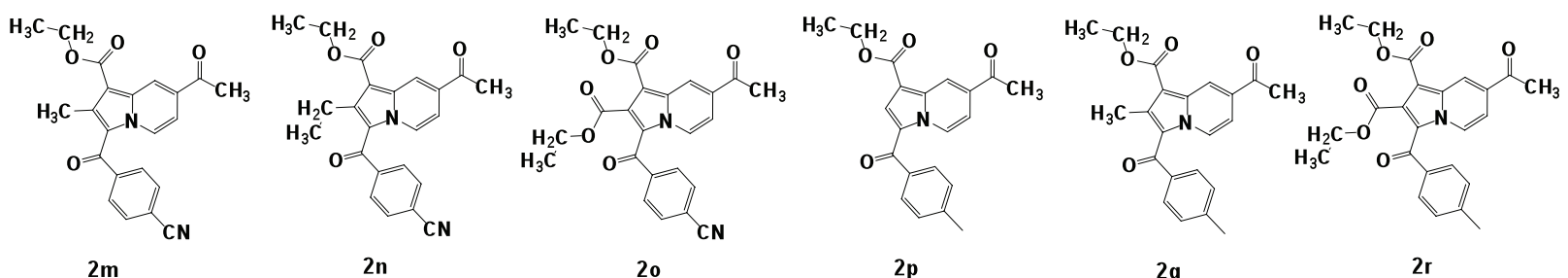

Figure 1. Molecular structure and code of indolizine analogs used for in vitro qualitative anti-TB activity.

properties, such as their analgesic (Vaught et al., 1990), anti-cancer (Butler, 2008; Sandeep et al., 2016a), anti-diabetic (Mederski et al., 2012; January 31), anti-histaminic (Cingolani et al., 1990), antiinflammatory (Hagishita et al., 1996; Sandeep et al., 2017; 2018b), anti-leishmanial (Jaisankar et al., 2004), anti-microbial (Hazra et al., 2011), anti-mutagenic (Olejnikova et al., 2009), antioxidant (Nasir et al., 1998), anti-tubercular (Dannhardt et al., 1987; Khedr et al., 2018), antiviral (Mishra and Tiwari, 2011), larvicidal
(Sandeep et al., 2016b; 2018a), in vitro, and herbicidal activities (Smith et al., 2005).

With these observations in mind, and in continuation of our efforts to develop novel heterocyclic (Khedr et al., 2018; Venugopala et al., 2013; 2016; 2018) and peptide (Narayanaswamy et al., 2011) compounds with anti-TB activity and to screen pharmacologically active heterocyclic compounds based on their polymorphic properties (Munshi et al., 2004; 
Table 1. Anti-tubercular activity against H37Rv strain of M. tuberculosis.

\begin{tabular}{|c|c|c|c|c|}
\hline \multirow[b]{2}{*}{ Compound code } & \multicolumn{4}{|c|}{ Concentration $(\mu \mathrm{g} / \mathrm{ml})$} \\
\hline & $c \log \mathrm{P}^{\mathrm{a}}$ & 25 & 50 & 100 \\
\hline $2 a$ & 1.5990 & $\mathrm{~S}$ & $\mathrm{~S}$ & $\mathrm{~S}$ \\
\hline $2 b$ & 2.1814 & $\mathrm{~S}$ & $\mathrm{~S}$ & $\mathrm{~S}$ \\
\hline $2 \mathrm{c}$ & 2.8312 & $\mathrm{~S}$ & $\mathrm{~S}$ & $\mathrm{~S}$ \\
\hline $2 d$ & 4.4772 & $\mathrm{R}$ & $\mathrm{R}$ & $\mathrm{R}$ \\
\hline $2 \mathrm{e}$ & 5.0062 & $\mathrm{R}$ & $\mathrm{R}$ & $\mathrm{R}$ \\
\hline $2 \mathrm{f}$ & 3.4512 & S & S & $\mathrm{S}$ \\
\hline $2 \mathrm{~g}$ & 3.4012 & S & S & $\mathrm{S}$ \\
\hline $2 \mathrm{~h}$ & 5.0472 & $\mathrm{R}$ & $\mathrm{R}$ & $\mathrm{R}$ \\
\hline $2 \mathbf{i}$ & 4.0212 & S & S & $\mathrm{S}$ \\
\hline $2 j$ & 3.5512 & $\mathrm{~S}$ & S & $\mathrm{S}$ \\
\hline $2 \mathrm{k}$ & 5.1972 & $\mathrm{R}$ & $\mathrm{R}$ & $\mathrm{R}$ \\
\hline 21 & 4.1712 & $\mathrm{~S}$ & S & $\mathrm{S}$ \\
\hline $2 \mathrm{~m}$ & 3.8200 & $\mathrm{R}$ & $\mathrm{R}$ & $\mathrm{R}$ \\
\hline $2 n$ & 4.3490 & $\mathrm{R}$ & $\mathrm{R}$ & $\mathrm{R}$ \\
\hline 20 & 2.7843 & S & $\mathrm{S}$ & $\mathrm{S}$ \\
\hline $2 p$ & 3.1840 & S & $\mathrm{S}$ & $\mathrm{S}$ \\
\hline $2 q$ & 4.8300 & $\mathrm{R}$ & $\mathrm{R}$ & $\mathrm{R}$ \\
\hline $2 \mathbf{r}$ & 3.8061 & S & $\mathrm{S}$ & $\mathrm{S}$ \\
\hline Streptomycin & & S & $\mathrm{S}$ & $\mathrm{S}$ \\
\hline Pyrazinamide & & $\mathrm{S}$ & $\mathrm{S}$ & $\mathrm{S}$ \\
\hline
\end{tabular}

Note: ${ }^{\mathrm{a}} \mathrm{c} \log P$ was calculated using the software package ChemBioDraw Ultra $13.0 \mathrm{v}$ (PerkinElmer Inc., Waltham, MA).

$\mathrm{R}$ indicates resistivity and $\mathrm{S}$ indicates the sensitivity of the tested compounds against the standard in different concentrations.

Panini et al., 2014a; 2014b), we evaluated synthesized (Sandeep et al., 2016a) ethyl 7-acetyl-2-substituted-3-(4-substituted benzoyl)indolizine-1-carboxylate analogs $\mathbf{2 a - r}$ (Scheme 1; Fig. 1) to determine their qualitative anti-TB activity in vitro using an agar dilution method against a susceptible H37Rv strain (Table 1).

\section{MATERIALS AND METHODS}

The synthetic route for the construction of indolizine scaffolds $\mathbf{2 a}-\mathbf{r}$ and the characterization of the title compounds are described in our earlier research publication (Sandeep et al., 2016a). The synthetic ethyl 7-acetyl-2-substituted-3-(4-substituted benzoyl) indolizine-1-carboxylates $\mathbf{2 a}-\mathbf{r}$ have been tested for their qualitative anti-TB activity in vitro against an $M$. tuberculosis $\mathrm{H} 37 \mathrm{Rv}$ strain.

\section{Anti-tubercular activity}

The procedure followed for anti-TB screening involves the use of Middlebrook $7 \mathrm{H} 9$ broth and the M. tuberculosis strain H37Rv. The basal medium was prepared in accordance with the manufacturer's instructions (HiMedia Laboratories, Mumbai, India) and sterilized by autoclaving; $4.5 \mathrm{ml}$ of broth was added into each sterile bottle. To this, $0.5 \mathrm{ml}$ of Oleic acid dextrose catalase (OADC) supplement was added, which contained catalase, bovine serum albumin, and dextrose fraction. A volume of $10 \mathrm{mg} / \mathrm{ml}$ stock solution of the test compound was then prepared. From this, an appropriate amount of solution was transferred to media bottles to achieve concentrations of 25,50 , and $100 \mu \mathrm{g} / \mathrm{ml}$. Then, $10 \mu \mathrm{l}$ of a suspension containing the $M$. tuberculosis H37Rv strain $(100,000$ organisms/ml, adjusted by McFarland's turbidity standard) was transferred to each tube and incubated at $37^{\circ} \mathrm{C}$. In addition, one growth control without the compound and drug controls was established. The bottles were examined twice a week to determine growth, for a total period of 3 weeks. Turbidity was considered as growth and was indicative of resistance to the compound. Growth was confirmed by taking a smear from each bottle and conducting a Ziehl-Neelsen (ZN) stain. The antibiotic standards used included streptomycin $(7.5 \mu \mathrm{g} / \mathrm{ml})$ and pyrazinamide $(7.5 \mu \mathrm{g} / \mathrm{ml})$.

\section{RESULTS AND DISCUSSION}

The in vitro qualitative anti-TB activity was tested for all of the 2a-r derivatives using the M. tuberculosis strain H37Rv at 25,50 , and $100 \mu \mathrm{g} / \mathrm{ml}$ by an agar dilution method (Sun et al., 2010) (Table 1). Test compounds $\mathbf{2 a}, \mathbf{2 b} \mathbf{2 c}, \mathbf{2 f}, \mathbf{2 g}, \mathbf{2 i}, \mathbf{2 j}, \mathbf{2}, \mathbf{2}$, $2 \mathbf{p}$, and $2 \mathbf{r}$ were found to be active against $M$. tuberculosis at all three concentrations. Compounds 2d, 2e, 2h, 2k, 2m, 2n, and $2 \mathbf{p}$ were found to be inactive against $M$. tuberculosis at all three concentrations. The common functionality of inactive compounds $\mathbf{2 d}, \mathbf{2 e}, \mathbf{2 h}, \mathbf{2 k}, \mathbf{2 m}, \mathbf{2 n}$, and $\mathbf{2 p}$ was the presence of a diethyl ester group at position 1 and a methyl or ethyl group at position 2 . The common functionality of active compounds $\mathbf{2 a}, \mathbf{2 b} \mathbf{2 c}, \mathbf{2 f}, \mathbf{2 g}, \mathbf{2 i}$, $\mathbf{2 j}, \mathbf{2}, \mathbf{2 0}, \mathbf{2} \mathbf{p}$, and $\mathbf{2 r}$ was the presence of a diethyl ester group at position 1 , and either hydrogen or diethyl ester at position 2 . The acetyl group was found at position 7 and the substituted benzoyl group was noted at position 3 of the indolizine nucleus.

\section{CONCLUSION}

In an attempt to select promising indolizine compounds $(\mathbf{2} \mathbf{a}-\mathbf{r})$ to determine their quantitative anti-TB activity, test compounds 2a, 2b 2c, 2f, 2g, 2i, 2j, 2l, 2o, 2p, and 2r were active against the $M$. tuberculosis H37Rv strain, while test compounds $\mathbf{2 d}, \mathbf{2 e}, \mathbf{2 h}, \mathbf{2 k}, \mathbf{2 m}, \mathbf{2 n}$, and $\mathbf{2 p}$ were found to be inactive against the M. tuberculosis $\mathrm{H} 37 \mathrm{Rv}$ strain. Based on the preliminary results, we proposed to design and synthesize novel indolizine scaffolds having various functional groups for anti-TB activity against multidrug-resistant strains of $M$. tuberculosis.

\section{ACKNOWLEDGMENTS}

The authors would like to thank Sahyadri Science College, Shimoga, for providing laboratory facilities and Maratha Mandal NGS Institute of Dental Science, Belgaum, India for carrying out anti-tubercular activity. KNV would like to thank the National Research Foundation (Grant Nos. 96807 and 98884), South Africa and Durban University of Technology, South Africa, for their support and encouragement.

\section{COMPETING INTERESTS} interests.

The authors declare that they have no competing

\section{REFERENCES}

Bloch AB, Cauthen GM, Onorato IM, Dansbury KG, Kelly GD, Driver CR, Snider DE Jr. Nationwide survey of drug-resistant tuberculosis in the United States. JAMA, 1994; 271:665-71.

Butler MS. Natural products to drugs: natural product-derived compounds in clinical trials. Nat Prod Rep, 2008; 25:475-516. 
Cingolani GM, Claudi F, Massi M, Venturi F. Indolizine derivatives with biological activity VI 1-(2-aminoethyl)-3-benzyl-7methoxy-2-methylindolizine, benanserin structural analogue. Cingolani, $1990 ; 25: 709-12$.

Dannhardt G, Meindl W, Gussmann S, Ajili S, Kappe T. Antimycobacterial 7-hydroxy-2,3-dihydro- $1 H$-indolizin-5-ones. Eur J Med Chem, 1987; 22:505-10.

Hagishita S, Yamada M, Shirahase K, Okada T, Murakami Y, Ito Y, Matsuura T, Wada M, Kato T, Ueno M, Chikazawa Y, Yamada K, Ono T, Teshirogi I, Ohtani M. Potent inhibitors of secretory phospholipase A2: synthesis and inhibitory activities of indolizine and indene derivatives. $\mathrm{J}$ Med Chem, 1996; 39:3636-58.

Halab L, Becker JA, Darula Z, Tourwe D, Kieffer BL, Simonin F, Lubell WD. Probing opioid receptor interactions with azacycloalkane amino acids. Synthesis of a potent and selective ORL1 antagonist. J Med Chem, 2002; 45:5353-7.

Hazra A, Mondal S, Maity A, Naskar S, Saha P, Paira R, Sahu KB, Paira P, Ghosh S, Sinha C, Samanta A, Banerjee S, Mondal NB. Amberlite-IRA-402 $(\mathrm{OH})$ ion exchange resin mediated synthesis of indolizines, pyrrolo [1,2-a] quinolines and isoquinolines: antibacterial and antifungal evaluation of the products. Eur J Med Chem, 2011; 46:2132-40.

Jaisankar P, Pal B, Manna KN, Pradhan PK, Medda S, Basu MK, Giri VS. Synthesis of antileishmanial (5R)-(-)-5-carbomethoxy-3-formyl5,6-dihydroindolo-[2,3-a]-indolizine. ARKIVOC, 2004; 2003:150-7.

Khedr MA, Pillay M, Sandeep C, Chopra D, Aldhubiab BE, Attimarad M, Alwassil OI, Mlisana K, Odhav B, Venugopala KN. Molecular modeling studies and anti-TB activity of trisubstituted indolizine analogues; molecular docking and dynamic inputs. J Biomol Struct Dyn, 2018; 36:2163-78.

Kochi A, Vareldzis B, Styblo K. Multidrug-resistant tuberculosis and its control. Res Microbiol, 1993;144:104-10.

Mederski W, Beier N, Burgdorf LT, Gericke R, Klein M, Tsaklakidis C. Indolizine derivatives and the use thereof as antidiabetics. US Patent; January 31, 2012, p. 8.

Michael JP. Simple indolizidine and quinolizidine alkaloids. Alkaloids Chem Biol, 2001;55:91-258.

Michael JP. Indolizidine and quinolizidine alkaloids. Nat Prod Rep, 2002; 19:719-41.

Mishra BB, Tiwari VK. Natural products in drug discovery: clinical evaluations and investigations. Opportunity Challenge Scope Nat Prod Med Chem, 2011; 1-61.

Munshi P, Venugopala KN, Jayashree BS, Row TNG. Concomitant polymorphism in 3-Acetylcoumarin: role of weak $\mathrm{C}-\mathrm{H} \cdots \mathrm{O}$ and $\mathrm{C}-\mathrm{H} \cdots \pi \pi$ Interactions. Cryst Growth Des, 2004; 4:1105-7.

Nagesh HK, Padmashali B, Sandeep C, Yuvaraj T, Siddesh MB. Synthesis and antimicrobial activity of benzothiophene substituted coumarins, pyrimidines and pyrazole as new scaffold. Int J Pharm Sci Rev Res, 2014; 28(2):6-10.

Narayanaswamy VK, Albericio F, Coovadia YM, Kruger HG, Glenn EM, Pillay M, Govender T. Total synthesis of a depsidomycin analogue by convergent solid phase peptide synthesis and macrolactonization strategy for anti-tubercular activity. J Peptide Sci, 2011; 17:683-9.

Nasir AI, Gundersen LL, Rise F, Antonsen O, Kristensen T, Langhelle B, Bast A, Custers I, Haenen GR, Wikstrom H. Inhibition of lipid peroxidation mediated by indolizines. Bioorg Med Chem Lett, 1998; 8:1829-32.

Nunn P, Williams B, Floyd K, Dye C, Elzinga G, Raviglione M. Tuberculosis control in the era of HIV. Nat Rev Immunol, 2005; 5:819.

Olejnikova P, Birosova L, Svorc L. Antimicrobial and antimutagenic properties of newly synthesized derivatives of indolizine. Sci Pharm, 2009;77:216.

Panini P, Venugopala KN, Odhav B, Chopra D. Polymorphism in two biologically active dihydropyrimidinium hydrochloride derivatives: quantitative inputs towards the energetics associated with crystal packing. Acta Crystallogr Sect B Struct Sci Cryst Eng Mater, 2014a; 70:681-96.
Panini P, Venugopala KN, Odhav B, Chopra D. Quantitative analysis of intermolecular interactions in 7-Hydroxy-4-methyl-2H-chromen2-one and Its Hydrate. Proc Natl Acad Sci India Sect A, 2014b; 84:281-95.

Pearson WH, Hembre EJ. Synthesis of novel glycosidaseinhibitory hydroxymethyl-substituted polyhydroxylated indolizidines: ring-expanded analogs of the pyrrolizidine alkaloids alexine and australine. J Organ Chem, 1996; 61:5546-56.

Rastogi N, Ross BC, Dwyer B, Goh KS, Clavel-Seres S, Jeantils $\mathrm{V}$, Cruaud P. Emergence during unsuccessful chemotherapy of multiple drug resistance in a strain of Mycobacterium tuberculosis. Eur J Clin Microbiol Infect Dis, 1992; 11:901-7.

Sandeep C, Padmashali B, Kulkarni RS. Efficient synthesis of indolizines and new imidazo[1,2-a]pyridines via the expected cyclization of aromatic cycloimmonium ylides with electron deficient alkynes and ethyl cyanoformate. Tetrahedron Lett, 2013; 54:6411-4.

Sandeep C, Padmashali B, Venugopala KN, Kulkarni RS, Venugopala R, Odhav B. Synthesis and characterization of ethyl 7-acetyl2-substituted 3-(substituted benzoyl)indolizine-1-carboxylates for in vitro anticancer activity. Asian J Chem, 2016a; 28:1043-8.

Sandeep C, Venugopala KN, Gleiser RM, Chetram A, Padmashali B, Kulkarni RS, Venugopala R, Odhav B. Greener synthesis of indolizine analogues using water as a base and solvent: study for larvicidal activity against Anopheles arabiensis. Chem Biol Drug Des, 2016b; 88:899-904.

Sandeep C, Venugopala KN, Khedr MA, Padmashali B, Kulkarni RS, Rashmi V, Odhav B. Design and synthesis of novel indolizine analogues as COX-2 inhibitors: computational perspective and in vitro screening. Indian J Pharm Educ Res, 2017; 51:452-60.

Sandeep C, Venugopala KN, Nayak SK, Gleiser RM, García DA, Kumalo HM, Kulkarni RS, Mahomoodally FM, Venugopala R, Mohan MK, Odhav B. One-pot microwave assisted synthesis and structural elucidation of novel ethyl 3-substituted-7-methylindolizine-1-carboxylates with larvicidal activity against Anopheles arabiensis. J Mol Struct, 2018a; 1156:377-84.

Sandeep C, Venugopala KN, Tratrat C, Mahomoodally FM, Aldhubiab BE, Haroun M, Venugopala R, Mohan MK, Kulkarni RS, Attimarad MV, Harsha S, Odhav B. Efficient synthesis and characterization of novel indolizines: exploration of in vitro COX-2 inhibitory activity and molecular modelling studies. New J Chem, 2018b;42:4893-901.

Siddesh M, Basavaraj P, Thriveni K, Sandeep C. Synthesis of thiophene-linked pyrimidopyrimidines as pharmaceutical leads. J Chem Sci, 2014; 126:821-6.

Smith SC, Clarke ED, Ridley SM, Bartlett D, Greenhow DT, Glithro H, Klong AY, Mitchell G, Mullier GW. Herbicidal indolizine-5,8diones: photosystem I redox mediators. Pest Manag Sci, 2005; 61:16-24.

Sun Z, Zhang J, Song H, Zhang X, Li Y, Tian M, Liu Y, Zhao $\mathrm{Y}, \mathrm{Li}$ C. Concomitant increases in spectrum and level of drug resistance in Mycobacterium tuberculosis isolates. Int J Tuberculosis Lung Dis, 2010; 14:1436-41.

Thriveni KS, Padmashali B, Siddesh MB, Sandeep C. Synthesis of pyrimidine incorporated piperazine derivatives and their antimicrobial activity. Indian J Pharm Sci, 2014; 76:332-8.

Vaught JL, Carson JR, Carmosin RJ, Blum PS, Persico FJ, Hageman WE, Shank RP, Raffa RB. Antinociceptive action of McN-5195 in rodents: a structurally novel (indolizine) analgesic with a nonopioid mechanism of action. J Pharmacol Exp Ther, 1990; 255:1-10.

Venugopala KN, Chandrashekharappa S, Pillay M, Bhandary S, Kandeel M, Mahomoodally FM, Morsy MA, Chopra D, Aldhubiab BE, Attimarad M, Alwassil OI, Harsha S, Mlisana K. Synthesis and structural elucidation of novel benzothiazole derivatives as anti-tubercular agents: insilico screening for possible target identification. Med Chem, 2018; doi:10. 2174/1573406414666180703121815.

Venugopala KN, Rao GD, Bhandary S, Pillay M, Chopra D, Aldhubiab BE, Attimarad M, Alwassil OI, Harsha S, Mlisana K. Design, synthesis, and characterization of (1-(4-aryl)-1H-1, 2, 3-triazol-4-yl) 
methyl, substituted phenyl-6-methyl-2-oxo-1, 2, 3, 4-tetrahydropyrimidine5-carboxylates against Mycobacterium tuberculosis. Drug Des Develop Ther, 2016; 10:2681.

Venugopala KN, Susanta KN, Pillay M, Renuka P, Yacoob MC, Odhav B. Synthesis and antitubercular activity of 2-(substituted phenyl/benzyl-amino)-6-(4-chlorophenyl)-5-(methoxycarbonyl)-4methyl-3,6-dihydropyrimidin-1-ium chlorides. Chem Biol Drug Des, $2013 ; 81: 219-27$.
How to cite this article:

Chandrashekharappa S, Venugopala KN, Venugopala R, Padmashali B. Qualitative anti-tubercular activity of synthetic ethyl 7-acetyl-2-substituted-3-(4-substituted benzoyl) indolizine-1-carboxylate analogs. J Appl Pharm Sci, 2019; 9(02):124-128. 